\title{
O "DIÁLOGO INSTITUCIONAL" EM DEMANDAS DE SAÚDE: O DILEMA ENTRE A EFETIVIDADE E A EFICIÊNCIA DESTE DIREITO SOCIAL.
}

\author{
Elísio Augusto Velloso Bastos* \\ Jacob Arnaldo Campos Farache*
}

\section{Resumo:}

Apesar da ampla proteção aos direitos sociais atualmente, há ainda quem defenda que estes direitos não possuem "dentes”, ou seja, não podem ser exigíveis do Estado. Esta é uma tese cada vez mais combatida, porém que se renova constantemente com argumentos novos. Recentemente, nasceu o chamado "diálogo institucional", uma espécie de requisito, que preceitua uma consulta e conversa prévia dos juízes com órgãos públicos antes de decidir demandas sobre o tema saúde. Enfim, este artigo analisa a relação entre este instrumento e a efetividade de direitos fundamentais.

\section{Palavras-chave:}

Direitos Sociais; Políticas Públicas de Saúde; Efetividade; Eficiência; Diálogo Institucional.

\author{
THE “INSTITUTIONAL DIALOGUE” IN HEALTH DEMANDS: THE DILEMMA
} BETWEEN THE EFFECTIVENESS AND THE EFFICIENCY OF THIS SOCIAL LAW.

\begin{abstract}
:
* Doutor em Direito do Estado pela faculdade de Direito da Universidade de São Paulo (USP). Professor em Direitos Humanos e em Teoria Geral da Constituição (Graduação) e em Teoria da Constituição no Centro Universitário do Estado do Pará- CESUPA. Coordenador do Grupo de Pesquisa Inteligência Artificial, Democracia e Direitos Fundamentais. Procurador do Estado do Pará. Advogado. https://orcid.org/0000-00018183-5920. E-mail: elisio.bastos@ uol.com.br. Avenida Conselheiro Furtado, 1625, apto. 1801, Cremação, CEP: 66.040-100, Belém, Pará, Brasil.

* Mestrando em Direito, Políticas Públicas e Desenvolvimento Regional pelo Centro de Ensino Superior do Pará (CESUPA). Especialista em Direito Público pela Pontifícia Universidade Católica de Minas Gerais (PUC/MG), Especialista em Direito e Processo do Trabalho pela Universidade Anhanguera (UNIDERP/MS), Especialista em Docência do Ensino Superior pelo Centro Universitário do Estado do Pará (CESUPA) e Especialista em Planejamento e Gestão do Desenvolvimento Regional pela Universidade Federal do Pará (UFPA). Juiz de Direito no Tribunal de Justiça do Estado do Pará. Professor de Direito Civil da Faculdade de Itaituba - FAI. Orcid: https://orcid.org/0000-0003-2480-2027. E-mail: jacob.farache@ gmail.com.
\end{abstract}


Despite the wide protection or social rights nowadays, there are still those who defend that these rights do not have "teeth", that is, they cannot be demanded from the State. This is an increasingly contested thesis, but it is constantly renewed with new arguments. Recently, the so-called "institutional dialogue" was born, a kind of requirement, which requires prior consultation and conversation between judges and public bodies before deciding demands involving health issues. Anyway, this article will analyze the relationship between this instrument and the effectiveness of fundamental rights.

\section{Keywords:}

Social Rights; Public Health Policies; Effectiveness; Efficiency; Institutional Dialogue.

\section{INTRODUÇÃO}

Em demandas de saúde, o tempo é um fator relevante muitas vezes esquecido pelos operadores do direito. Aguardar a tramitação processual, para quem necessita de um atendimento ou tratamento médico ou mesmo de medicamentos, pode representar a irreversibilidade de um quadro clínico grave ou mesmo a morte.

Neste cenário de urgência, de acordo com dados do Conselho Nacional de Justiça (CNJ), aproximadamente um milhão e oitocentos mil ações foram ajuizadas até 31.12.2017 no Poder Judiciário, discutindo questões relativas à saúde no Brasil, sendo que a maioria dessas demandas visa assegurar um direito social expressamente previsto em diversas normas internacionais e na própria Constituição da República de 1988, ou seja, o direito à saúde.

A relevância de assegurar-se o direito à saúde parece ser consenso na doutrina e na jurisprudência. O grande problema reside, talvez, na forma como isto deve ser efetivado pelo Poder Público e, em especial, pelo Estado-juiz.

Muitas correntes e questões emergem quando é ajuizada uma demanda judicial em busca de alguma prestação que busque efetivar o Direito à saúde. Há quem sustente a "Reserva do Possível”, a separação de poderes, a tutela do "mínimo existencial”, etc. No entanto, mais recentemente, surgiu e vem ganhando espaço o chamado "diálogo institucional", ou seja, um canal de comunicação em que o Poder Judiciário discute, previamente com outros órgãos do Poder Público, questões relacionadas a demandas de 
saúde propostas em juízo.

Este artigo visa analisar uma questão de ordem prática e simples: "Solucionar as demandas de saúde através do chamado 'diálogo institucional', é mais efetivo para assegurar este direito social aos jurisdicionados?”. Por óbvio, esta questão perpassa pela análise dos efeitos das decisões judiciais sobre este campo do direito. Logo, para caminhar sobre este caminho proposto, contemplou-se este artigo em quatro capítulos, a presente introdução e conclusão, são eles: a) Os pactos da Organização das Nações Unidas (ONU) e a inexigibilidade dos direitos sociais; b) $\mathrm{O}$ direito à saúde na Constituição da República de 1988; c) Desconstruindo certas falácias acerca dos direitos sociais; e d) A efetivação do direito à saúde, a política pública do "diálogo institucional" e o papel do Poder Judiciário na construção de uma proteção efetiva ao jurisdicionado.

Enfim, por óbvio, tal percurso não tem como objetivo a completude, seja porque o instrumento escolhido é limitado (artigo) seja porque a intenção é limitada em realizar uma reflexão de ordem prática para um dilema que envolve a efetivação dos direitos à saúde no ambiente forense.

\section{OS PACTOS DA ORGANIZAÇÃO DAS NAÇÕES UNIDAS (ONU) E A(IN)EXIC}

Antes de se analisar a questão das demandas de saúde e as complicações na solução destas demandas judiciais, cabe apresentar a origem dos direitos sociais no ambiente jurídico atual, em especial, demonstrar o fundamento histórico e jurídico construído por aqueles quelutaram pela defesa destes direitos na construção do mundo após a Segunda Guerra Mundial.

Os direitos sociais foram consagrados na Declaração Universal dos Direitos Humanos (DUDH) de 1948, mais especificamente, entre os seus artigos XXII e XXVII. Não obstante, os direitos declarados na DUDH foram acolhidos nos textos constitucionais de diversos Estados mundo afora.

A DUDH é, em síntese, um marco decisivo de internacionalização de direitos. No entanto, do ponto de vista formal, a DUDH é uma mera resolução da Assembleia Geral das Nações Unidas, possuindo caráter de mera recomendação sem caráter jurídico vinculante (PORTELA, 2017).

Posteriormente, no intuito de alterar esta realidade e objetivando a criação de 
normas jurídicas vinculantes para os Estados que se encontrem sob sua jurisdição, advieram os pactos internacionais. Primeiramente, surgiu o Pacto Internacional de Direitos Civis e Políticos (PIDCP) em 1966.

O PIDCP trouxe 53 (cinquenta e três) artigos e foi incorporado pelo ordenamento jurídico brasileiro através do Decreto $n^{\circ}$ 592/1992. Basicamente, este pacto adveio com diversas normas que promoviam o respeito universal e efetivo aos direitos e liberdades do homem, tais como: autodeterminação dos povos (artigo $1^{\circ}$ ); proibição à discriminação (artigo $2^{\circ}$ ); igualdade entre homens e mulheres (artigo $3^{\circ}$ ); direito à vida (artigo $6^{\circ}$ ); proibição à tortura (artigo $7^{\circ}$ ); vedação à escravidão (artigo $8^{\circ}$ ); direito à liberdade (artigo $9^{\circ}$ ); o direito de liberdade de locomoção (artigo 12); o direito à um devido processo legal (artigo 14); o direito à liberdade de pensamento, de consciência e de religião (artigo 18), etc.

Deveras, muitos direitos civis e políticos foram previstos no PIDCP, porém os direitos humanos ainda careciam da sua proteção no âmbito econômico, social e cultural, o que fora alcançado com o chamado "Pacto Social".

O Pacto Internacional dos Diretos Econômicos, Sociais e Culturais (PIDESC) também foi elaborado em 1966 e promulgado no Brasil pelo Decreto ${ }^{\circ}$ 591/1992. Neste pacto, objetiva- se a promoção e proteção de direitos econômicos, sociais, e culturais, assegurando: o direito ao trabalho (artigo $6^{\circ}$ ); liberdade sindical (artigo $8^{\circ}$ ); previdência social (artigo $9^{\circ}$ ); proteção à família (artigo 10); o direito à dignidade (artigo 11); o direito à saúde (artigo 12); direito à educação (artigo 13); o direito à vida cultural (artigo 15), etc.

Certamente, o rol de direitos econômicos, sociais e culturais previsto no PIDESC mostra-se extremamente amplo e se fosse atendido pelo Estados nacionais, a realidade socioeconômica seria outra. No entanto, o próprio PIDESC prevê no seu corpo uma válvula de escape para que muitos países, mesmo que tenham ratificado o pacto, escusem-se de suas obrigações. Cuida-se do artigo $2^{\circ}$, do "Pacto Social", o qual prevê expressamente que serão adotas medidas para assegurar o pleno exercício dos direitos sociais "até o máximo de recursos disponíveis". Indo além, o mesmo dispositivo permite que se limite os direitos ali estabelecidos que não sejam seus nacionais.

Este artigo do PIDESC preve a possibilidade dos Estados nao assegurarem direitos economicos, sociais e culturais quando nao haja recursos para tanto. Nao ha previsao semelhante no PIDCP. Infelizmente, isso possibilita que omissoes estatais sejam justificadas com teorias como da reserva do possivel e afins 
Sustenta-se, ainda, que a estratégia da Comissão de Direitos Humanos, responsável pela elaboração do PIDCP e do PIDESC, era dividir os direitos humanos em dois grupos para assim obter o maior número de países, ratificando os pactos e ampliando o alcance destes direitos ao redor do mundo (PORTELA, 2017). Todavia, considerando a redação empregada no artigo $2^{\circ}$, do PIDESC, que condiciona a efetividade pretendida para os direitos econômicos, sociais e culturais, não haveria grande distinção a elaboração de um pacto único, uma vez que estes direitos poderiam ser escusados pelos Estados sob o argumento de que não há recursos disponíveis? Estaé uma pergunta retórica, pois não há elementos científicos claros e isto seria um anacronismo desnecessário. Interessante, todavia, é observar que, em 1969, o Pacto de São José da Costa Rica (Decreto n 678/1992) não fez esta divisão, protegendo, tanto direitos civis e políticos (artigos $3^{\circ}$ a 25) quanto econômicos, sociais e culturais (artigo 26) no mesmo documento internacional (PIOVESAN, 2019).

Independentemente de se tratar de dois pactos distintos ou um pacto único, observa-se que tais argumentos encontram fundamento na afirmação de que direitos civis e políticos seriam distintos de direitos econômicos, sociais e culturais em sua estrutura.

Abramovich e Courtis (2011) expõem que aqueles que entendem que direitos sociais não são exigíveis defendem uma distinção na natureza destes direitos em relação aos direitos civis e políticos. Argumenta-se que estes geram apenas obrigações negativas ou de abstenção, enquantoos direitos econômicos, sociais e culturais representam o nascimento de obrigações positivas que na maioria envolvem a utilização de recursos públicos.

Outrossim, há quem defenda que os direitos sociais possuem um caráter de "prestação", o que também seria uma diferença desses dos direitos civis e políticos. A respeito, Abramovich e Courtis (2011) discordam e apontam que os direitos sociais possuem, na realidade, duas facetas: uma mais visível de obrigação de fazer e outra menos perceptível de não-fazer. Tem-se, nas palavras destes autores, que:

Não resulta difícil descobrir a existência concomitante de obrigação de não fazer: o direito à saúde implica na obrigação estatal de não causar danos à saúde; o direito à educação supõe estatal de não causar danos à saúde; o direito à educação supõe a obrigação de não piorar a educação; o direito à preservação de um meio ambiente saudável implica na obrigação de não destruir o meio ambiente. 
Em suma, os direitos econômicos, sociais e culturais também podem ser caracterizados como um complexo de obrigações positivas e negativas por parte do Estado, ainda que neste caso, para identificá-los, as obrigações positivas tenham uma importância simbólica maior. (2011, p. 33-34).

Desse modo, conclui-se que eventuais distinções entre estas espécies de direitos humanos não têm sentido, tanto porque muitos direitos tidos tradicionalmente por civis e políticos estão sofrendo reinterpretação num sentido social quanto porque retirar a possibilidade de se exigir de um determinado poder judicial que atue na defesa de um direito descumprido compromete a própria plenitude da existência deste direito (ABRAMOVICH e COURTIS, 2011).

Em síntese, nascem diversos argumentos que tentam enfraquecer a exigibilidade dos direitos sociais e, no direito à saúde, por sua vez, não é diferente. No entanto, conforme se observa, tais argumentos não merecem prosperar, vez que o respeito aos direitos econômicos, sociais e culturais é essencial e sua inobservância deve conduzir impreterivelmente para uma resposta estatal apta a concretizá-lo, sob pena de esvaziar a própria existência deste direito humano.

\section{O DIREITO À SAÚdE NA CONSTITUIÇÃO DA REPÚBLICA DE 1988: BREVESCONSIDERAÇÕES}

O direito fundamental à saúde está inserto no rol dos direitos e garantias fundamentais, encontrando previsão expressa no artigo $6^{\circ}$, da Constituição da República de 1988. É uma espécie de direito social, sendo que este consiste, em verdadeiro poder de se exigir perante o Estado, responsável por atender a esse rol de direitos, a contraprestaçăo sob forma de prestaçăo dos serviços de natureza social (FERREIRA FILHO, 2008).

Com efeito, o direito público subjetivo à saúde representa prerrogativa jurídica indisponível assegurada à generalidade das pessoas pela própria Constituição da República (artigo 196). A respeito, esclarece Ladeira (2009, p. 110) que o "direito à saúde configura-se como direito social prestacional que objetiva assegurar à pessoa humana condições de bem-estar e de desenvolvimento mental e social livre de doenças físicas e psíquicas".

Traduz-se, na realidade, num bem jurídico constitucionalmente tutelado, por cuja 
integridade deve velar, de maneira responsável, o Poder Público, a quem incumbe formular e implementar políticas sociais e econômicas idôneas que visem a garantir aos cidadãos o acesso universal e igualitário à assistência farmacêutica e médico-hospitalar (MENDES e BRANCO,2017).

Nos direitos sociais, conforme já exposto alhures, reside a dificuldade de se concretizar a proteção estatal. A este respeito, asseveram Sarlet, Marinoni e Mitidiero (2018, p. 678):

Por mais que os poderes públicos, como destinatários precípuos de um direito à saúde, venham a opor - além da já clássica alegação de que o direito à saúde (a exemplo dos direitos sociais prestacionais em geral) foi positivado como norma de eficácia limitada - os habituais argumentos da ausência de recursos e da incompetência dos órgãos judiciários para decidirem sobre a alocação e destinação de recursos públicos, não nos parece que esta solução possa prevalecer, ainda mais nas hipóteses em que está em jogo a preservação do bem maior da vida humana.

Felizmente, a jurisprudência segue a mesma linha e pensamento, ou seja, efetivar o direito à saúde, conforme exegese que faz do julgamento de lavra do Ministro Celso Mello, na relatoria do Recurso Extraordinário no 393.175/RS, quando discorre sobre a importância da garantia e efetivação desse direito em nosso país, a saber:

Cumpre não perder de perspectiva que o direito público subjetivo à saúde representa prerrogativa jurídica indisponível assegurada à generalidade das pessoas pela própria Constituição da República. Traduz bem jurídico constitucionalmente tutelado, por cuja integridade deve velar, de maneira responsável, o Poder Público, a quem incumbe formular - e implementar políticas sociais e econômicas que visem a garantir, aos cidadãos, o acesso universal e igualitário à assistência médico-hospitalar.

$[\ldots]$

Nesse contexto, incide sobre o Poder Público a gravíssima obrigação de tornar efetivas as prestações de saúde, incumbindo-lhe promover, em favor das pessoas e das comunidades, medidas - preventivas e de recuperação -, que, fundadas em políticas públicas idôneas, tenham por finalidade viabilizar e dar concreção ao que prescreve, em seu art. 196, a Constituição da República.

Do julgado acima, extrai-se que o Supremo Tribunal Federal (STF) reconheceu a necessidade de se tornar efetiva a prestação de saúde, a fim de "viabilizar e dar concreção ao 
que prescreve" a Magna Carta. Sob outro prisma, pode-se argumentar que este julgado impossibilita a utilização de argumentos que esvaziem o direito à saúde, sob a alegação de que dependem disto ou daquilo para sua efetivação pelo Estado.

No entanto, a questão gira em torno, muitas vezes, de qual é o ente federativo competente para efetivar o direito à saúde. Por óbvio, a repartição da competência, prevista no artigo 196, da Constituição da República de 1988, não pode, de forma alguma, servir de escusaou demora para efetivação deste direito social tão relevante ao cidadão.

Em apertada síntese, ocorre que o constituinte definiu, tanto a instituição de um sistema único e integrado de saúde quanto suas atribuições (MENDES e BRANCO, 2017). Para regular mais o assunto, advieram as Leis $n^{\circ} 8.142 / 1990$ e 8.080/1990.

Por seu turno, a Constituição de 1988 foi expressa no seu artigo 23, inciso II, quando prevê a competência comum da União, dos Estados, do Distrito Federal e dos Municípios para "cuidar da saúde e assistência pública, da proteção e garantia das pessoas portadoras de deficiência". Esta divisão de competência permite a conclusão de que todos os entes federativos são responsáveis solidários pela saúde junto ao indivíduo e à coletividade (MENDES e BRANCO, 2017).

No mesmo sentido, o STF já pacificou tal solidariedade no julgamento do RE 626.382- $\mathrm{AgR}$, onde ficou consignada a responsabilidade solidária dos entes federativos quanto ao fornecimento de medicamentos pelo Estado, podendo o interessado pleiteá-los de qualquer um deles - União, Estados, Distrito Federal ou Municípios.

Em suma, ja ha um entendimento tanto na doutrina quanto na jurisprudência como na legislação (artigo 16, da Lei no 8.080/1990) de que o direito à saúde deve ser concretizado e que a responsabilidade é solidária entre os entes federados: Uniao, Estados, Distrito Federal e Municípios.

\section{DESCONSTRUINDO CERTAS FALÁCIAS ACERCA DOS DIREITOS SOCIAIS}

Por conseguinte, considerando que tanto em âmbito internacional quanto em âmbito nacional, é dever do Estado assegurar os direitos econômicos, sociais e culturais. No Brasil, não é diferente, sobretudo, porque nosso país se encontra obrigado, tanto por normas internas de sua própria elaboração (Constituição de 1988 e Leis n 8.142/1990 e 8.080/1990) quanto 
por pactos internacionais que ratificou (Decretos $n^{\circ}$ 591/1992 e 678/1992). Logo, seria razoável concluir-se que os direitos sociais, em especial, o direito à saúde seria facilmente exigível do Estado brasileiro.

Infelizmente, a realidade não se apresenta dessa forma. Barreto (2013) elenca os argumentos mais rotineiros das teses que tentam desconstruir os direitos sociais e argumenta que estas seriam intituladas de "falácias dos direitos sociais".

Primeiramente, os direitos sociais seriam de segunda ordem. O autor argumenta que os direitos humanos são uma construção histórica, na qual se formou, primeiramente, os direitos civis e políticos num ambiente de Estado liberal clássico e, posteriormente, os sociais advieram e integraram-se numa relação de reciprocidade através de um processo político dentro de um Estado Democrático de Direito. Todavia, os direitos civis e políticos passaram a pressupor a realização dos direitos sociais. Assim, os direitos sociais representam uma fonte substantiva de igualdade material e liberdade real, sendo que sua concretização significa, em última instância, a própria defesa dos direitos fundamentais em si (BARRETO, 2013).

A segunda falácia residiria no argumento de que direitos sociais exigem economias estatais fortes. Entretanto, este argumento não encontra guarida quando se observa que economias fortes também defendem a exclusão dos direitos sociais da categoria dos direitos fundamentais, o que seria um verdadeiro retrocesso social (BARRETO, p. 2013)

A terceira falácia diz respeito ao custo dos direitos sociais frente aos recursos orçamentários existentes. É a chamada teoria da reserva do possível. Todavia, Barreto (2013) expõe que o custo é consubstancial a todos os direitos fundamentais, vez que não se pode olvidar dos altos custos estatais para garantir o aparato estatal administrativo-judicial em funcionamento para atender os direitos civis e políticos. Portanto, a escassez de recurso não se justifica para afastar apenas direitos sociais, vez que todos os direitos fundamentais têm custos para o Estado.

Silva (2008, p. 593) acrescenta, ainda, que embora "seja correta a tese que a realização e a garantia de qualquer direito custa dinheiro, também é verdade que a realização dos direitossociais e econômicos custa mais dinheiro".

De forma mais ampla e abrangendo também o direito à saúde, assevera Canotilho (2008, p. 97) que os direitos sociais, "na qualidade de direitos fundamentais, devem regressar ao espaço jurídico-constitucional, e ser considerados como elementos 
constitucionais essenciais de uma comunidade jurídica bem ordenada". Logo, a essencialidade do direito à saúde é inerente à uma sociedade.

Reforçando tudo que já foi dito e seguindo a mesma linha, Sarlet, Marinoni e Mitidiero (2018, p. 655) contribuem para a linha argumentativa de que o argumento dos custos não podem impedir a efetivação dos direitos sociais, a saber:

O ponto possivelmente mais polêmico em termos de exigibilidade dos direitos sociais como direitos subjetivos e fundamento para o controle jurisdicional de políticas públicas (ambas as situações, apesar de seus pontos de contato, não se confundem) diz respeito à assim chamada "reserva do possível", ou seja, com a dimensão economicamente relevante dos direitos sociais (embora já se reconheça que tal relevância econômica não é apenas dos direitos sociais) na condição de direitos a prestações estatais, de modo especial, naquilo que guardam relação com a destinação, criação e (re)distribuição de recursos materiais e humanos, com destaque para os aspectos econômicos, financeiros e tributários que dizem respeito à efetividade dos direito sociais.

Conquanto se reconheça que todos os direitos sempre acarretam "custos" para sua efetivação e proteção, sejam direitos civis, sejam direitos políticos ou sociais, o fato é que, em termos de exigibilidade judicial, o apontado "fator custo" nunca constituiu elemento impeditivo de efetivação da dimensão negativa (função de defesa) dos direitos sociais, pelo menos não no sentido de se advogar a impossibilidade de provimento judicial com base nos direitos civis e políticos, pelo menos quando não em causa pretensões de objeto positivo, ou seja, implicando prestações estatais. A concessão de uma ordem de habeas corpus, por exemplo, não é colocada na dependência do fato de que há poucos juízes disponíveis ou pouco investimento emsegurança pública, ou seja, o reconhecimento da pretensão (e do direito subjetivo negativo) fundada na liberdade de locomoção, embora também dependa, em parte, de pressupostos de ordem fática, entre outros, não é obstado em virtude de tal circunstância e não se questiona também a aplicabilidade imediata e eficácia plena da norma queassegura a liberdade de locomoção.

Logo, observa-se que não se pode argumentar nenhuma destas falácias acima para se defender a inaplicabilidade dos direitos sociais, sob pena de criar o que se chama de direitos "sem dentes", ou seja, direitos que não encontram respaldo na força da lei (SUSTEIN e HOLMES, 2011). Os direitos sociais, em especial, o direito à saúde encontra seus fundamentos em diversas normas nacionais e internacionais. Logo, não é caso de não se ter dentes, mas de tê-los em excesso e mesmo assim não poder morder.

\section{A EFETIVAÇÃo IMEDIATA DO DIREITO À SAÚDE OU O "DIÁlOGO}




\section{INSTITUCIONAL": QUAL O PAPEL DO PODER JUDICIÁRIO NA CONSTRUÇÃO DE UMA PROTEÇÃO EFETIVA AO JURISDICIONADO?}

O acesso à saúde no Brasil talvez seja uma das mais profundas chagas da sociedade brasileira. Aparentemente, os anos passam, governos mudam, políticas públicas são alteradas, leis são criadas, etc. Enfim, tudo é feito, mas o serviço público de saúde em nosso país parece que sempre é insuficiente, sendo que muitas vezes nem mesmo o básico é garantido pelo Estado aos cidadãos.

Silva (2008) expõe que os direitos sociais não possuem tanta efetividade porque seuscustos são mais elevados que dos direitos civis e políticos, bem como aponta que uma solução encontrada recentemente seria a implementação de políticas públicas que permitam um diálogo constitucional entre instituições (Poder Judiciário e Executivo), a fim de apurar a forma como os recursos estão sendo alocados e, se for necessário, questionar tais alocações de recursos públicos.

Deveras, a linha argumentativa do autor é bem convincente e possui uma prática democrática intrínseca bem atraente. A realidade também já se mostra neste caminho, uma vezque diversos canais de comunicação estão sendo criados pelos Tribunais para realizar estediálogo entre o Poder Judiciário e outros setores do Poder Público, justamente, na tentativa de encontrar soluções eficientes para demandas envolvendo questões de saúde.

Surge, assim, o chamado "diálogo institucional", ou seja, uma ferramenta utilizada para mitigar a judicialização de demandas, através da criação de canais de comunicação diretos para solucionarem uma determinada situação. Originariamente, este instituto tem origem canadense e refere-se, geralmente, a interações entre os Poderes, buscando a troca de argumentos racionais, a abstenção de decidir acerca de determinados pontos ou desenvolver suas próprias decisões com fundamentos em decisões tomadas por outras instituições (CLÈVE e LORENZETTO, 2015).

A tese do "diálogo institucional" visa superar os "monólogos". Há, basicamente, dois modelos de diálogos institucionais: um normativo e outro instrumental. O primeiro seria muito utilizado pelas Cortes Superiores para legitimar suas decisões e combater o caráter contramajoritário das decisões judiciais. O segundo, por sua vez, consiste no instrumento de interação entre poderes na construção de uma solução que envolve outros agentes políticos, 
alémdo Poder Judiciário (CLÈVE e LORENZETTO, 2015).

A ideia de se criar um espaço em que agentes políticos construam, em conjunto, uma solução para uma demanda de saúde mostra-se um valioso instrumento de pacificação social. Seguindo esta linha, os "diálogos institucionais" seriam o remédio para o ativismo judicial (SILVA, 2008). Por ativismo, entende-se "uma participação mais ampla e intensa do Judiciário na concretização dos valores e fins constitucionais" (BARROSO, 2010, p. 291).

Silva (2008), por sua vez, aduz que o ativismo judicial não é uma possibilidade no contexto judicial atual por uma série de razões: depende de diversas mudanças estruturais na educação jurídica, a organização dos tribunais e os próprios procedimentos judiciais não são instrumentos aptos. A respeito, este autor assevera:

O Judiciário não deve distribuir medicamentos ou bens similares de forma irracional a indivíduos, ele deveria ser capaz de canalizar as demandas individuais e, em uma espécie de diálogo constitucional, exigir explicações objetivas e transparentes sobre a alocação de recursos públicos por meio das políticas governamentais, de forma a estar apto a questionar tais alocações com os poderes políticos sempre que necessário for. (2008, p. 598).

Apesar do respeito devido ao entendimento esposado por Silva (2008), este artigo tenta mostrar uma exceção importante e contrária a universalização do "diálogo institucional" como instrumento para tratamento de demandas de saúde, qual seja: as demandas de saúde urgentes, nas quais o tempo necessário para construção de uma decisão em conjunto, o que impossibilita a aplicação universal do "diálogo institucional” em demandas de saúde.

Não obstante, a agregação de conhecimentos advindos de diferentes fontes mostrase muito atraente. Alinhando-se aos argumentos favoráveis a este "diálogo institucional" em demandas de saúde, tem-se que o direito não é uma ciência que se basta, sendo importante analisar fenômenos sociais, a partir de uma perspectiva mais ampla, um viés interdisciplinar (CARDOSO, 2015; GONÇALVES e STELZER, 2014), o que pode ser feito com a inserção, por exemplo, de um viés econômico.

Aparentemente, este é o olhar lançado por aqueles que argumentam que a efetividade de direitos sociais demanda de recursos econômicos para serem efetivados. É uma Análise Econômica do Direito (AED) que fazem os doutrinadores quando apontam que 
decisões judiciais devem respeitar a "reserva do possível" ou mesmo realizar diálogos constitucionais antes de se imiscuir nesta ou naquela política pública de saúde.

Uma breve exposição desta linha pensamento jurídico contemporâneo, parece demonstrar como ela se alinha perfeitamente aos argumentos daqueles que entendem que direitos sociais não possuem "dentes” próprios.

Em apertada síntese, a AED pode ser entendida como "a aplicação da teoria econômica e dos métodos econométricos no exame da formação, da estrutura, dos processos e dos impactos do direito e das instituições legais para uma maior eficiência alocativa a fim de alcançar o bem-estar dentro da moral" (SANTOS FILHO, 2016, p. 216).

Posner é um dos principais nomes quando se trata da AED (COPETTI NETO e MORAIS, 2011; FERNANDEZ, 2013). Ele foi vanguardista na aplicação desta teoria em áreas como o direito de família e direito constitucional (GONÇALVES; STELZER, 2014). A publicação da obra de Posner Economic analisys of law, em 1973, consolidou a teoria da AED (SANTOS FILHO, 2016). Para Posner, os juízes podem e devem utilizar princípios econômicos no processo decisório para melhor a aplicação da lei, levando em consideração os seus efeitos (LEITE, 2017).

O “juiz de Posner" enfrentaria três desafios:

Em primeiro lugar, o juiz deve possuir conhecimento, informação e experiência suficientes para poder determinar a regra legal eficiente isoladamente. Em segundo lugar, o juiz deve ser capaz de determinar se a regra eficiente isoladamente é também a regra eficiente quando incorporada e interagindo com outras regras legais relevantes. Mas, finalmente, o juiz deve ser capaz de discernir como a norma jurídica interage com outras normas não jurídicas que podem ser relevantes para a decisão (ZYWICKI e SANDERS, 2020, p. 17)

Feitas tais considerações, é necessário reconhecer que há limitações para AED (FERNANDEZ, 2013) e estas podem ser encontradas nas demandas de saúde levadas diariamente ao Poder Judiciário. Algumas das críticas da AED amoldam-se, perfeitamente, nas características intrínsecas de demandas de saúde e merecem destaque, quais sejam: a) o enfoque na eficiência econômica não pode afastar o fim dos modelos institucionais

1 " [...] First, the judge must possess sufficient learning, information, and expertise to be able to determine the efficient legal rule in isolation. Second, the judge must be able to determine whether the efficient rule in isolation is also the efficient rule when embedded in and interacting with other relevant legal rules. But finally, the judge must be able to discern how the legal rule interacts with other non-legal rules that may be relevant to the determination" 
estabelecidos em especial no pós $2^{\mathrm{a}}$ Guerra Mundial, que é o de reconhecer e tutelar direitos fundamentais básicos em caráter universal (COPETTI NETO e MORAIS, 2011); e b) não é possível também que se conheça por completo a realidade, para que se consiga pensar de uma forma total em seus efeitos e consequências (FERNANDEZ, 2013).

Analisando a primeira crítica, observa-se que a AED não serve para afastar direitos fundamentais (COPETTI NETO e MORAIS, 2011). O direito à saúde é um direito social fundamental reconhecido expressamente após 1945 em diversos diplomas normativos internacionais, conforme exposto alhures neste artigo. Logo, uma análise das consequências da decisão que afasta a efetivação de um direito social tão relevante não é de vanguarda, mas um verdadeiro retrocesso social sob uma nova roupagem.

A segunda crítica, por sua vez, é um exercício de humildade para qualquer agente público e, em especial, para o juiz. Em casos de saúde, não se tem como saber por completo a realidade e nem os efeitos de um tratamento médico ou de um remédio, vez que a medicina não é uma ciência exata. Logo, exigir do juiz que ele analise as consequências de sua decisão é um mito, pois nem um médico o poderia fazê-lo. Logo, não há como se conhecer ou controlar por completo uma decisão judicial em questões de saúde.

Então, resta a dúvida: como proceder com estes "diálogos institucionais" sem perder de vista a efetividade que o direito à saúde exige nos casos concretos? A resposta que se mostra possível é que dependerá do caso concreto, porque, conforme já exposto alhures, um fator que parece ser decisivo para se escolher o caminho a ser seguido pelo Poder Judiciário, mais especificamente, pelo julgador é o tempo.

Nas próprias palavras de Silva (2008), é preciso encontrar o meio termo para a questão. No entanto, este caminho do meio deve ser encontrado caso a caso. Analisando de forma prática, pode-se apresentar dois casos exemplificativos.

Num primeiro caso, o autor demanda por um medicamento que toma mensalmente para tratamento de uma doença. Observa-se, então, um caso que permite um "diálogo institucional" na busca por saber se tal medicamento possui previsão na Relação Nacional de Medicamentos Essenciais (RENAME) ou se possui similar. Enfim, existe um prazo que não comprometerá a vida do autor caso seja iniciado um “diálogo institucional” entre o Poder Judiciário e outros órgãos do Poder Público.

Num segundo caso, por sua vez, tem-se como autor um recém-nascido que precisa ser levado para Unidade Terapia Intensiva Pediátrica (UTI Pediátrica), podendo perder a 
vida em poucas horas. Nestes casos, não há como se iniciar um "diálogo institucional" para avaliar o destino mais eficiente dos recursos públicos. O caminho a ser seguido para assegurar o direito à saúde é simples: decisão imediata e esperar que vida consiga ser salva pelos profissionais da saúde.

Abramovich e Courtis (2011) pareciam já ter previsto a dificuldade natural que o Poder Judiciário tem em realizar planejamentos de políticas públicas. Logo, exigir este "diálogo institucional" em demandas de saúde urgentes é o mesmo que não proteger, adequadamente, esse direito social tão relevante para os cidadãos.

Logo, eventual necessidade oitiva prévia de outros órgãos públicos é medida que deve ser tomada a depender de cada caso concreto e deve ser perseguida por todos os operadores do direito, conforme nos ensina a doutrina:

Dentre os demais aspectos apontados no campo da realização dos direitos a prestações, situa-se a (alegada) necessidade de um "diálogo institucional", fundado, por um lado, na noção de um déficit em termos de capacidade institucional (técnica) por parte do Poder Judiciário (o mesmo se aplica aos demais agentes da esfera jurídica, como é o caso do Ministério Público, da Defensoria Pública, entre outros) no sentido de lidar de forma proficiente com certas demandas, mas que também pode, além disso, ser reconduzido à noção de uma necessidade de cooperação produtiva entre os órgãos (poderes) estatais. (SARLET, MARINONI e MITIDIERO, 2018, p. 661).

Não obstante, gerenciar um "diálogo institucional” com a celeridade necessária para assegurar que a prestação jurisdicional seja efetiva é um tanto quanto utópico.

Por conseguinte, em que pese posições contrárias, o caminho do ativismo judicial não é pernicioso ou mesmo um mal necessário para sociedade, bem como não deve ser refutado a qualquer custo. Muito pelo contrário, a atuação deve ser "cum grano salis", sobretudo, em respeito aos ditames constitucionais e para assegurar a defesa de direitos fundamentais. A respeito, leciona Canotilho (2006, p. 220):

O Judiciário deve esforçar-se por compreender que a norma está sempre ligada ao problema concreto. Assim, apesar dos formalismos jurídicos, há que se captar as dimensões fundamentais do problema, até porque algumas dessas dimensões radicam na consciência profunda da comunidade. A minha posição é, portanto, que os juízes não são órgãos de transformação social, mas, em alguns casos, eles apontam um caminho importante de concretização da constituição. 
Não obstante, gerenciar um “diálogo institucional” com a celeridade necessária para assegurar que a prestação jurisdicional seja efetiva é um tanto quanto utópico.

Observa-se, assim, que não é lícito ao poder público negar direitos sociais sob qualquer pretexto, sob pena de se violar direitos humanos fundamentais previstos, tanto em pactos internacionais quanto na Constituição da República de 1988.

Bedaque (2007) nos lembra que o amesquinhamento da função jurisdicional torna os juízes meros controladores de exigências formais e enfraquecem as características principais da atividade jurisdicional, quais sejam: o reestabelecimento da ordem jurídica material, a eliminação de litígios e manter a paz social.

Nos exemplos acima relatados, pode-se observar que a efetividade de decisões judiciais no âmbito da saúde não pode ser prejudicada por argumentos que visem trazer supostamente eficiência à políticas públicas da área. Isto seria prejudicial, sobretudo, para os jurisdicionados e num momento que costuma ser extremamente crítico.

Em síntese, o direito à saúde deve prevalecer sobre possíveis argumentos econômicos de eficiência, devendo ser observada a realidade e a necessidade de cada caso concreto para se fixar o procedimento a ser adotado na solução da demanda de saúde proposta perante o Poder Judiciário.

\section{CONCLUSÃO}

Os direitos econômicos, sociais e culturais são uma construção histórica relevantíssimana sociedade ocidental. Relegá-los a um segundo plano é um retrocesso social que deve ser combatido por qualquer operador do direito e, com muito mais razão, por quem deve assegurar direitos fundamentais do cidadão: o juiz.

Observou-se que os direitos sociais foram previstos em diversas normas internacionais e nacionais. No âmbito internacional, tem-se a Declaração Universal dos Direitos do Humanos (DUDH), o Pacto Internacional dos Direitos Econômicos, Sociais e Culturais (PIDESC) e o Pacto de São José da Costa Rica. No âmbito nacional, tem-se a própria Constituição de 1988 e as Leisn ${ }^{8} .142 / 1990$ e 8.080/1990.

Na doutrina, apesar de posicionamentos contrários, observa-se que os argumentos que defendem a desnecessidade de se efetivar direitos sociais não encontram guarida numa análise mais crítica sobre seus fundamentos. Logo, entendimentos que tentam limitar 
tais direitos, cada vez, mais representam um retrocesso social e histórico para sociedade humana.

Neste cenário, emerge o instituto conhecido por "diálogo institucional”, no qual se prega que, antes de uma decisão judicial em demandas de saúde, o magistrado deve consultar outros agentes públicos para verificar as consequências de sua decisão junto ao Poder Público.

Com a devida vênia a entendimentos contrários, este artigo pretendeu demonstrar a inviabilidade de se universalizar tal procedimento em demandas de saúde, pois tal medida significaria uma violação de direitos fundamentais diversos.

Primeiramente, a demora pode significar violação ao direito de acesso à justiça (artigo $5^{\circ}$, inciso XXXV, da Constituição de 1988), pois representaria negar o acesso do cidadão à uma prestação jurisdicional efetiva quando ele mais precisa dela, ou seja, quando estiver acometido de uma patologia grave.

Em segundo lugar, violação do direito à saúde propriamente dito, pois representaria a utilização de instrumentos que dilatariam o tempo da resposta judicial à demanda, podendo comprometer a própria utilidade da decisão judicial quando, finalmente, fosse prolatada.

Com efeito, estes argumentos contrários à uma atuação judicial asseguradora dos direitos sociais, mostram-se bem persistentes e renovam-se, gradativamente, com novos institutos ou argumentos jurídicos.

No entanto, o caminho é o meio termo, ou seja, encontrar o ponto de equilíbrio entre os "diálogos institucionais" e os casos em que decisões judiciais têm que ser cumpridas imediatamente para assegurar a vida de cidadãos. Este caminho é mais complexo, porém é o que se mostra adequado, neste momento histórico, sobretudo, para assegurar a eficiência de políticas públicas de saúde sem perder de vista a necessária efetividade de decisões judiciais sobre o tema.

Enfim, o ideal seria ter uma visão do conjunto, mas esta dialeticidade é limitada, complexa e quiçá utópica. Para agravar a situação, em muitos casos, não há tempo de construí-la. Logo, reconhecendo tais limitações, é preciso se confiar nos valores que se pretende proteger e respeitar: o direito fundamental à saúde das pessoas, não olvidando do exíguo tempo para fazê-lo em muitos casos.

\section{REFERÊNCIAS}


ABRAMOVICH, Victor; COURTIS. Christian. Direitos sociais são exigíveis. Porto Alegre:Editora Dom Quixote, 2011. 
ATRIA, Fernando. ¿Existen Derechos Sociales? Alicante: Biblioteca Virtual Miguel de Cervantes, 2005. Edición digital a partir de Discusiones: Derechos Sociales, núm. 4 (2004), p. 15-59. Disponível em: http://www.cervantesvirtual.com/obra/existen-derechos-sociales-0/ Acesso em: 20 jan. 2021.

BARRETTO, Vicente de Paulo. O fetiche dos direitos humanos e outros temas. 2. ed. rev. e ampl. Porto Alegre: Livraria do Advogado Editora, 2013.

BARROSO, Luís Roberto. Curso de direito constitucional contemporâneo: os conceitos fundamentais e a construção do novo modelo. 2. ed. São Paulo: Saraiva, 2010.

BASTOS, Elísio e DOU, Heloisa. A Fundamentalidade dos Direitos Sociais à luz da teoria dos custos dos direitos e do debate entre Fernando Atria e Carlos Pulido. Revista Direito, Estado e Sociedade, n. 57, p. 75-109, jun./set. 2020. Disponível em: https://revistades.jur.pucrio.br/index.php/revistades/article/view/1012/598 Acesso em: 20 jan. 2021.

BEDAQUE, José Roberto dos Santos. Efetividade do processo e técnica processual. 2. ed. São Paulo: Malheiros, 2007.

BOBBIO, Norberto. A Era dos Direitos. Rio de Janeiro, Campus, 1992.

BRASIL. Constituição (1988). Constituição da República Federativa do Brasil. Disponível em: <http://www.planalto.gov.br/ccivil 03/Constituicao/Constituicao.htm>. Acesso em: 05 ago. 2020.

RE 393175 AgR, Relator(a): CELSO DE MELLO, Segunda Turma, julgado em 12/12/2006, DJ 02-02-2007 PP-00140 EMENT VOL-02262-08 PP-01524.

RE 626382 AgR, Relator(a): ROSA WEBER, Primeira Turma, julgado em 27/08/2013,ACÓRDÃO ELETRÔNICO DJe-178 DIVULG 10-09-2013 PUBLIC 11-09-2013.

CANOTIlHO, José Joaquim Gomes. Direito Constitucional e Teoria da Constituição. 2. ed.Coimbra: Almedina, 2006.

Estudos sobre Direitos Fundamentais. São Paulo: Revista dos Tribunais, 2008.

CARDOSO, Germano Bezerra. Análise econômica do direito, políticas públicas e consequências.

Revista Jurídica da Presidência, Brasília, v. 17, n. 112, p. 293-313, jun./set. 2015.

CLÈVE, Clèmerson Merlin; LORENZETTO, Bruno Meneses. Diálogos institucionais: estruturae legitimidade. Revista de Investigações Constitucionais, Curitiba, v. 2, n. 3, p. 183206, set./dez. 2015. Disponível em: < https://revistas.ufpr.br/rinc/article/view/44534> Acesso 
em: 28 jan. 2021.

COPETTI NETO, Alfredo; MORAIS, José Luis Bolzan de. O Segundo Movimento Law And Economics, a Eficiência e o consenso do Modelo Neoclássico Ordenalista Subjetivista a partir de Richard Posner: ruptura ou (re)aproximação ao (estado de) direito contemporâneo. Constituição, 
Economia e Desenvolvimento. Revista da Academia Brasileira de Direito Constitucional,

Curitiba, v. 3, n. 4, p. 56-76, jan./jun. 2011. Disponível em:

http://www.abdconst.com.br/revista5/segundoAlfredoJose.pdf Acesso em: 17 jan. 2021.

FERNANDEZ, Leandro. Metodologia da Pesquisa e a Análise Econômica Do Direito: fundamentos de uma abordagem consequencialista da investigação jurídica. Direito UNIFACS, Salvador, n. 156, 2013. Disponível em:

https://revistas.unifacs.br/index.php/redu/article/view/2659 Acesso em: 25 jan. 2021.

FERREIRA FILHO, Manoel Gonçalves. Direitos humanos fundamentais. 10. ed. Săo Paulo: Saraiva, 2008.

GONÇALVES, Everton das Neves; STELZER, Joana. Princípio da Eficiência EconômicoSocial no Direito Brasileiro: a tomada de decisão normativo-judicial. Seqüiência (Florianópolis), Florianópolis, n. 68, p. 261-290, jun. 2014. Disponível em:

https://www.scielo.br/pdf/seq/n68/12.pdf Acesso em 17 jan. 2021.

HOLMES, Stephen; SUNSTEIN, Cass. El Costo de Los Derechos: Por qué la libertad dependede los impuestos. Buenos Aires: Siglo Veintiuno Editores, 2011.

HORTA, Raul Machado. Direito Constitucional. 5. ed. rev. e atual. por Juliana Campos Horta. Belo Horizonte: Del Rey, 2010.

LADEIRA, Fernando de Oliveira Domingues. Direito à saúde: a problemática do fornecimento de medicamentos. Cadernos Jurídicos, São Paulo, v. 10, n. 32, p. 105-127, maio/ago. 2009.

LEITE, Geraldo Neves. A eficiência como fundamento jurídico da decisão judicial e o estado de coisas inconstitucional: uma abordagem crítica à luz do debate de Ronald Dworkin e Richard Posner. Dissertação (Mestrado em Direito, Políticas Públicas e Desenvolvimento Regional) - Programa de Pós-Graduação Strictu Sensu em Direito, Centro Universitário do Estado do Pará - CESUPA, Belém, 2017.

MENDES, Gilmar Ferreira; BRANCO, Paulo Gustavo Gonet. Curso de direito constitucional.

12. ed. rev. e atual. São Paulo: Saraiva, 2017.

MIRANDA, Jorge. Manual de Direito Constitucional. Tomo IV. Direitos Fundamentais. Coimbra: Coimbra Editora, 2000.

PIOVESAN, Flávia. Direitos humanos e justiça internacional: um estudo comparativo dos sistemas regionais europeu, interamericano e africano. 9. ed. rev. e atual. São Paulo: Saraiva 
Educação, 2019.

PORTELA, Paulo Henrique Gonçalves. Direito Internacional Público e Privado: incluindo Noções de Direitos Humanos e de Direito Comunitário. 9. ed. rev., atual. e ampl. Salvador: JusPODIVM, 2017.

REALE, Miguel. Lições Preliminares de Direito. 22. ed. São Paulo: Editora Saraiva, 1995.

SANTOS FILHO, Sírio Vieira dos A eficiência sob a perspectiva da análise econômica do direito. Justiça do Direito, Passo Fundo, v. 30, n. 2, p. 210-226, maio/ago. 2016. Disponível em: http://dx.doi.org/10.5335/rjd.v30i2.6040 Acesso em: 28 jul. 2020.

SARLET, Ingo Wolfgang; MARINONI, Luiz Guilherme; MITIDIERO, Daniel. Curso de direito constiucional. 7. ed. São Paulo: Saraiva Educação, 2018.

SILVA, José Afonso da. Curso de direito constitucional positivo. 24. ed. São Paulo: Malheiros, 2005.

SILVA, Virgílio Afonso da. O Judiciário e as Políticas Públicas: entre Transformação Social e Obstáculo à Realização dos Direitos Sociais. In: SILVA, Virgílio Afonso da. Direitos Sociais: Fundamentos, Judicialização e Direitos Sociais em Espécie. Rio de Janeiro: Lumen Juris, 2008. 